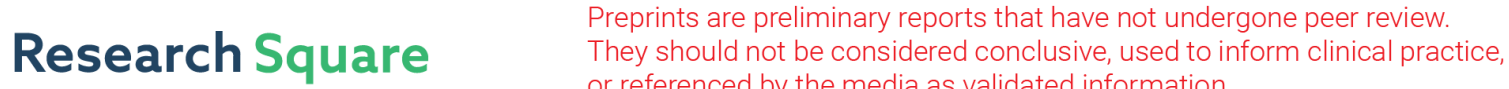 or referenced by the media as validated information. \\ Original vs Non-Original "Cast-To" Gold Abutment- Implant Connection: Analysis of the Internal Fit and Long-Term Fatigue Performance
}

\section{Raquel Alonso-Pérez}

Universidad Complutense de Madrid Facultad de Odontologia

José F. Bartolomé ( $\boldsymbol{D}$ jbartolo@icmm.csic.es)

Instituto de Ciencia de Materiales de Madrid https://orcid.org/0000-0002-7515-4202

Cristina Fraile

Universidad Complutense de Madrid Facultad de Odontologia

Guillermo Pradíes

Universidad Complutense de Madrid Facultad de Odontologia

Research article

Keywords: Cast-to gold abutment, internal accuracy, cyclic fatigue life

Posted Date: July 28th, 2020

DOI: https://doi.org/10.21203/rs.3.rs-42021/v1

License: (a) (i) This work is licensed under a Creative Commons Attribution 4.0 International License.

Read Full License 


\section{Abstract}

Background: Restoring implants with not original abutment-implant connection are widely used by clinicians. Due to the current scarcity of in-vitro studies about compatible abutments and lack of relevant clinical studies, long-term fatigue performance of non-original abutments should be analyzed. The aim of this research was to assess the internal accuracy and the cyclic fatigue life after artificial aging of three implant-abutment configurations restored with one original and two compatible non-original "cast-to" gold abutments.

Materials and Methods: Forty-eight original internal hexagon connection implants were connected to three different brands of abutments ( $n=16$ each): one original to the implant system and two nonoriginals.

Internal accuracy and the percentage of surface with tight contact were assessed under Scanning Electron Microscope (SEM) in twelve cross-sectioned samples at three different areas (platform, internal and screw).

To evaluate the fatigue mechanical behaviour under cyclic load, samples were loaded according to the ISO Norm 14801 in a universal testing machine at $2 \mathrm{~Hz}$ in air. Previously, samples were aged by thermocycling with 10,000 cycles at $5{ }^{\circ} \mathrm{C}$ and $55^{\circ} \mathrm{C}$ in artificial saliva.

Results: Original abutments presented the best accuracy and highest percentage of tight contact in the internal areas. Meanwhile, original abutments showed the lower cyclic fatigue strength degradation and the long-term success.

Conclusions: Occlusal loads are transferred more homogenously through the system when original abutments are used because the better fit between the different internal components. This fact provides the highest fatigue resistance for all the restorations studied.

\section{Background}

Implant therapy is the treatment of choice in the rehabilitation of missing teeth. It is a predictable treatment supported by high success rates [1]. One of the consequences of the development of implant therapy is the appearance of multiple implant companies. Some of them offer similar implant connection design, being possible to restore implants from one company with non-original prosthetic components but with unknown consequences for the longevity of the prostheses. Some studies have investigated the effect of interchanging components of different brands and they have found discrepancies with the original design [2-7]. Variations in the internal tolerances or design of the abutments can lead to modifications in the mechanical behaviour of the restoration. It can result in stress on the prosthetic screw leading to screw loosening or screw failure [3]. Moreover, the cyclic loading could also affect the formation of microgaps at the implant-abutment interface resulting in large differences in the overall contact areas $[8,9]$. Oral microbiome can proliferate in this microgap and affect peri-implant tissues, 
causing inflammation and peri-implant diseases $[10,11]$. The degree of bacterial penetration was influenced by the applied force, micromovement and precision fit at the implant-abutment interface [12, 13]. However, there are no systematic clinical studies of original versus non-original implant abutments and the information on long-term performance of "compatible" or "interchangeable" third-party abutments supporting cemented crowns is still scarce. Only clinical observations and experience of the investigators with an increasing frequency of technical complications can be detected [14]. Therefore, the long-term success of these implant-supported restorations requires analysis of their in vitro mechanical fatigue lifetime.

In this work, it was intended to determine the fatigue limit of the implant-abutment-crown complex for each group. Or what is the same, which is the load limit to which a specimen could survive for an infinite life. From the restorative point of view, this information is much more useful than the conclusions that could be drawn from a static load test $[2,3,15,16]$ where the specimens will then be subjected to a single-load test until fracture but, as we have seen before, this situation is far from reality and the conclusions obtained should be taken with caution.

On the other hand, to the best of our knowledge, there were no in vitro studies comparing mechanical outcomes and micromorphology at the implant-abutment interface of original versus non-original implant "cast-to" gold abutments. In the available studies, the abutments were produced using only three different types of fabrication methods; stock abutment, laser-sintered and milled abutment $[4,17,18]$.

Customized abutments can be both obtained using computer-aided design and computer-aided manufacturing (CAD/CAM) technologies or by traditional procedures in the dental laboratory (by UCLAtype abutments). Overcast abutments are composed by a premade metal base with a plastic cylinder that can be waxed and cast with the dental anatomy wished. The aim of this pre machined collar is to provide a perfect fit with the implant. It is usually made of gold or silver-palladium alloy presenting a melting range of around $1,280^{\circ} \mathrm{C}$ to $1,350^{\circ} \mathrm{C}$. For this reason, the alloy used to cast the cylinder should not be higher than $1,000^{\circ} \mathrm{C}[19]$. That justifies why they are usually overcast with a noble metal alloy, since Nickel-Chromium and Cobalt-Chromium alloys have a melting range of around $1,200^{\circ} \mathrm{C}$ and $1,315^{\circ} \mathrm{C}$. According to Vigolo [20], casting procedures with a high-fusing, gold-palladium alloy do not demonstrate any significant alteration of the original measurements of the abutment connection. "Cast-To" Gold Abutments are used to fabricate implant-level, custom cast restorations that provide subgingival margins for esthetics, reduced height for vertical occlusal clearance and/or custom angles.

The purpose of this study was to evaluate the internal accuracy and the mechanical properties under dynamic load of three different "cast-to" gold abutments for cement-retained restorations provided by different manufacturers. All of them connected to the same brand of internal hexagon connection implant.

The following null hypotheses will be tested: 1) There is no measurable difference in the internal fit between original and non-original abutments before loading. 2) There is no significant difference of 
mechanical integrity among cemented retained crowns implants connected to three different brands of "cast-to" gold abutments under cyclic loading.

\section{Methods}

\section{Sample preparation}

Forty-eight internal hexagon connection implants (TSV, Zimmer Biomet, Warsaw, IN, USA) with $3.5 \mathrm{~mm}$ platform were tested in the present study. Samples were divided randomly into three groups. Implants were connected to three different brands of "cast-to" gold abutments (Table 1):

- Original: 16 Zimmer Biomet implants + 16 Zimmer Biomet "Cast-To" Gold Abutments.

- Non-original 1: 16 Zimmer Biomet implants + 16 Gold Plastic Castable abutments (Implant Direct, California, USA).

- Non-original 2: 16 Zimmer Biomet implants + 16 Gold Plastic Cylinders (Medical Implant System, Shlomi, Israel).

Table 1

Manufacturer and composition of the abutments used in the present study

\begin{tabular}{|c|c|c|c|}
\hline Group & $\mathbf{N}$ & Composition & Brand name \& manufacturer \\
\hline Original & 16 & $\begin{array}{l}\text { Au-Pd Noble } \\
\text { alloy }\end{array}$ & $\begin{array}{l}\text { "Cast-To" Gold Abutment (Zimmer Biomet, Warsaw, IN, } \\
\text { USA) }\end{array}$ \\
\hline $\begin{array}{l}\text { Non-Original } \\
1\end{array}$ & 16 & $\begin{array}{l}\text { Au-Pd Noble } \\
\text { alloy }\end{array}$ & $\begin{array}{l}\text { Gold Plastic Castable (Implant Direct, } \\
\text { California, USA). }\end{array}$ \\
\hline $\begin{array}{l}\text { Non-Original } \\
2\end{array}$ & 16 & $\begin{array}{l}\text { Au-Pd Noble } \\
\text { alloy }\end{array}$ & $\begin{array}{l}\text { Gold Plastic Cylinder (Medical Implant System, } \\
\text { Shlomi, Israel) }\end{array}$ \\
\hline
\end{tabular}

All abutments consisted in a pre-machined standard cylinder with a plastic sleeve (Fig. 1). They were overcast with the same dimensions in a laboratory by one dental technician in an Au-Pd noble alloy (Protocol ${ }^{\circledR}$, Ivoclar Vivadent, Schaan, Liechtenstein) to obtain cemented abutments.

A torque gauge (Torque Wrench, Restorative TWR, Zimmer Biomet, Warsaw, IN, USA) previously calibrated was used to tighten the abutments to the implants according to the manufacturer instructions $(30 \mathrm{~N} \cdot \mathrm{cm})$ using Titanium Grade 5 (Ti-6Al-4V) screws supplied by each company. Polytetrafluoroethylene (PTFE) tape was used to fill the screw cavities of the abutments and provisional restorative material (Fermit $\mathrm{N}$, Ivoclar Vivadent, Schaan, Liechtenstein) was polymerized to cover them.

A first mandibular premolar was waxed, cast in cobalt chromium alloy (Remaniun Co-Cr alloy, Dentaurum, Ispringen, Germany) veneered with feldespathic ceramic (IPS d.SIGN, Ivoclar Vivadent, Schaan, 
Liechtenstein) in a standardized anatomy by means of a silicon mold. The metal-ceramic crowns were cemented to the "cast-to" gold abutments using adhesive resin cement (Multilink Implant, Ivoclar Vivadent, Schaan, Liechtenstein) using a cementing device connected to a manual torque wrench (no. 24075, Astra Tech, Mölndal, Sweden). It was used to ensure that the crown was loaded axially at a force of $20 \mathrm{~N} \cdot \mathrm{cm}$ until the complete seating of the material for 5 minutes. The anatomic shape of tooth crowns was chosen to ensure an in vitro setup, mimicking as much as possible the clinical situation.

\section{Internal fit}

To test the internal accuracy four samples of each group $(n=12)$ were embedded in a transparent acrylic resin (Tecmicro S.A., Madrid, Spain) using an automatic mounting press (Evolution, Remet, Italy). Samples were cut in the longitudinal axis using a microtome system with a diamond saw (Micromet $\mathrm{M}$, Remet, Italy) under water cooling. Laser markings on both sides of implant were used to indicate ideal positions for vertical sectioning. The final slice of each specimen was polished with silicon carbide abrasive papers ( 26 microns followed by 18 microns) under constant irrigation and finally with a silica suspension mixed with water. In order to minimize sample angulation and gap region distortion the pressure applied over the sample was uniform and the specimen's long axis was always perpendicular to grounding direction. An ultrasonic bath was used to remove the debris from the surface between the screw threads or implant fixture and from the abutment connection. The final slice of each specimen was examined with a scanning electron microscope (SEM Phenom ${ }^{\mathrm{TM}} \mathrm{G} 2$ pro SEM $5 \mathrm{kV}$, Eindhoven, Holland). Internal discrepancy was evaluated by two independent examiners with image analysis software (Phenom-World, Eindhoven, Holland). Kappa test was conducted to control the inter-examiner agreement. Mean gap and tight contact (TC) were measured at three different areas (Fig. 2):

- Platform area (I): it was defined as the surface of contact among the abutment and the shoulder of the implant.

- Internal area (II): the area of the abutment in contact with the internal connection of the implant.

- Screw area (III): the area of contact among the screw and the internal threads of the implant.

TC was considered when the gap among implant-abutment surface evaluated was equal or less than $4 \mu \mathrm{m}$ following the 2-dimensional (2D) methodology described by Mattheos et al [21] on the left and right sides of the slice. The percentage of TC was calculated for each area. Meanwhile, mean gap was evaluated in all the areas.

\section{Thermocycling and dynamic load test}

Firstly, twelve samples of each group $(n=36)$ were thermocycled alternating baths in artificial saliva at 5 ${ }^{\circ} \mathrm{C}$ and $55^{\circ} \mathrm{C}$ for 20 seconds with a period of 10 seconds between immersions for thermal stabilization for 10,000 cycles according to the ISO Norm 11405 [22]. Thermocycling is the in vitro process of subjecting a sample to extreme temperatures that comply with those found in the oral cavity [23]. Fusuyama-Meyer formula was used to prepare artificial saliva [24]. 
Secondly, samples were embedded in epoxy resin (Epoxicure Resin, Buehler, Illinois, USA) with a modulus of elasticity of approximately $4 \mathrm{GPa}$, similar to human mandibular bone [25]. The implants were placed in the centre of silicone molds at an angle of 90 degrees to the horizontal plane and with $3 \mathrm{~mm}$ vertical distance from the most coronal bone-to-implant border, simulating a vertical bone resorption of $3 \mathrm{~mm}$ according to the ISO-Norm 14801 [26]. All specimens were mounted at an angle of 30 degrees in relation to the loading cell in the universal testing machine $[27,28]$. A piece of tin foil with a thickness of $0.5 \mathrm{~mm}$ was placed over the crowns to achieve an even distribution of the load until fracture or deformation. Dynamic load test was conducted using a Shimadzu electromagnetic testing machine (EMT-1KNV-30, Kyoto, Japan) operated under load control at $2 \mathrm{~Hz}$ and with a sinusoidal wave form. All the fatigue tests were carried out in air at room temperature. The load ratio (minimum to maximum loading ratio) was equal to 10. The unidirectional cyclic loads selected for the start of the test were from - 30 to $-300 \mathrm{~N}$, simulating forces generated in the oral cavity [29]. If the fatigue failure or deformation of $2 \mathrm{~mm}$ takes place in three specimens at this load, the next specimens of the same group were subjected to decrease load progressively until no failure occurs to determine the "fatigue limit". Mechanical fatigue of the components do not occur in response to a stress level that is lower than a certain limit known as the fatigue limit, which represents the amplitude (or range) of cyclic stress that can be applied "infinitely" to the material without failure. This limit corresponds to the maximum load value to which at least three specimens survive and none fail until the reaching of 2 million cycles, which represents 5 years of simulated function [30].

After each test, the number of cycles and the load to failure values were recorded and represented in a plot of load versus the number of cycles to failure in semi logarithmic form ( $S-N$ curve) [31-33] showing the structure (implant + abutment + crown) fatigue performance. The data were obtained, using a specific computer application (Trapezium X software, Shimadzu).

Detailed fractographic inspection on tested samples was conducted after cyclic loading by SEM.

\section{Statistical analysis}

For the internal accuracy test, a sample size of 4 was required for a power of $80 \%$ and an alpha value of 0.05 [34]. Statistical analysis was executed using SPSS ${ }^{\circledR}$ software (version 21.0, SPSS Inc., Chicago, IL, USA). The chi square test was applied to identify statistically significant differences in the percentage of TC between original and non-originals groups in the three areas studied. After checking normality with Shapiro Wilk test $(p>0.05)$, mean gap in the different areas was compared with ANOVA. Post hoc Tukey test was used when significance was achieved. For all analysis, the level of significance was set at $\alpha=$ 0.05 .

\section{Results}

\section{Internal accuracy}


SEM photomicrographs documented the contact between the abutment and the implant at the different zones studied. In the platform area, mean gap was $<4 \mu \mathrm{m}$ in the three implant-abutment configurations, no differences were found in the percentage of TC either (Fig. 3). By contrast, in the internal and abutment screw areas (Figs. 4 and 5) the lower mean gaps were found in the original abutment group $(17.6 \mu \mathrm{m} \pm 2.5$ and $32 \mu \mathrm{m} \pm 1.9$ respectively). Meanwhile, in these areas percentages of surface with TC was significantly higher in original samples comparing to non-original abutments $(p=0.0001$ for internal area and $p=0.036$ for screw area). Percentages of TC mean gaps and standard deviations are shown in Table 2.

Table 2

Mean percentage of tight contact (\% of TC), mean gap and standard deviations for the different implant abutment configurations and areas.

\begin{tabular}{|lllllll|}
\hline Group/Area & \multicolumn{2}{l}{ Platform area } & \multicolumn{3}{l|}{ Internal area } & \multicolumn{2}{l|}{ Screw area } \\
\hline & \% of TC & Gap $(\mu \mathrm{m})$ & \% of TC & Gap $(\mu \mathrm{m})$ & $\%$ of TC & Gap $(\mu \mathrm{m})$ \\
\hline Original & 100 & $<4$ & 60.9 & $17.6 \pm 2.5$ & 27.3 & $32 \pm 1.9$ \\
\hline Non-Original 1 & 100 & $<4$ & $18.1^{*}$ & $20.3 \pm 3.7$ & 20.6 & $33.5 \pm 3.4$ \\
\hline Non-Original 2 & 100 & $<4$ & $12.5^{*}$ & $21.6 \pm 2.6$ & $10.8^{*}$ & $39.8 \pm 4.1^{*}$ \\
\hline *Significant differences found with the Original Group $(p<0.05)$ & & \\
\hline
\end{tabular}

\section{Fatigue load test}

The original configuration presented the highest fatigue limit value and the lowest fatigue strength exponent. Cyclic fatigue life was presented in a semi logarithmic form as maximum load (Pmax, $N$ ) versus cycles to failure $\left(N_{f}\right)$ (Fig. 6). A power-law regression equation (Basquin's law [35]) was used to fit the experimental fatigue data to determine the fatigue strength exponent of the specimens after plotting the Wohler stress-life (S-N) diagram which represents the cyclic mechanical degradation rate during fatigue loading. The regression confidence levels were $R^{2} \geq 0.96$, which was in good agreement with the experimental data. The original system showed a flatter S-N slope which represents a lower fatigue degradation rate. In contrast, non-original configurations showed a steeper S-N diagram, which led to a more significant decrease in fatigue strength. The fatigue limit, and fatigue strength exponent for all the specimens is shown in Table 3.

Table 3

Fatigue limit and fatigue strength exponent for the different implant-abutment configurations

\begin{tabular}{|lll|}
\hline Group & Fatigue limit $(\mathrm{N})$ & Fatigue strength exponent \\
\hline Original & 280 & -0.067 \\
\hline Non-original 1 & 200 & -0.104 \\
\hline Non-original 2 & 225 & -0.103 \\
\hline
\end{tabular}




\section{Failure Modes}

All fractures were registered in implants. The weakest point seemed to be the implant internal connection. However, two different patterns were found: 1) Implant and screw fracture at the first thread region resulted the most frequent failure mode of the non-original abutments. The portion of the implant in contact with the resin embedment acted as a level under off-axis loading, fractures were located at this point (Fig. 7A). 2) For the original abutment combinations, the failure mode observed was different and common to all the samples. The implant fracture point coincided with the apical extent of the abutment screw when fully seated. The original screw remained intact after loading (Fig. 7B).

\section{Discussion}

This study evaluated the internal accuracy and the fatigue mechanical integrity of three different implant abutment configurations. Original and non-original abutments showed good marginal fit between the implant and abutment. No microgap between the platform of the implant and the shoulder of the abutment could be detected before loading (Fig. 3). Intimate contact at this level is required to prevent or minimize ingress of bacterial contaminants. However, internal contact among both components was different. Original abutments presented enhanced fit between their components than non-original abutments. Meanwhile, the highest fatigue limit value and the lowest fatigue strength exponent was registered in the original configuration, thus first and second null hypothesis were rejected. The results of this research correlate with the study published by Binon [36] who stablish that a better fit and better contact between the abutment and implant surfaces lead to a better load distribution. TC between components was significantly higher when original components were used. The original abutments are milled for their specific implants with a tailor-made connection, which is supposed to improve the stability of the components, reducing the micromotion when the system is under cyclic loading. To the authors' opinion, this specific characteristic of the original abutments produce more homogeneous stress distribution between the components, improving the fatigue behaviour of the system.

Mattheos et al $[8,9,21]$ studied and compared the quality and quantity of contact between original and two compatible abutment brands in the cross section of the components. External and internal connection was evaluated finding significant better contact between original abutments and implants. The authors, however, indicated that the implant shoulder area was the surface where compatible abutments accuracy was closer to originals, which correlates with the findings observed in this research.

Therefore, internal accuracy determines the grade of friction between the surfaces, preventing micromotion and decreasing stress $[37,38]$ which improves the stability of the system. In the case of nonoriginal abutments the tendency of stress to concentrate at the abutment screw increased the risk for microfracture, and therefore for microgap formation. This was confirmed by the results of a previous investigation $[8,34]$ where original abutments after in vitro fatigue testing showed the best accuracy within their components as well as the lowest values of screw loosening. 
The aim of this investigation was to study the long-term stability of original and compatible "cast-to" gold abutments of different manufacturers with an internal hexagonal connection implants. All abutments were composed by the same noble alloy; however, fatigue behaviour of non-original abutments showed higher sensitivity to cyclic loading than originals. Non-originals configurations showed higher slopes in the S-N curves, which represents a higher risk of failure and microgap formation in a short period of time. As a result, the fatigue strength exponent was 1.5 times lower in the original configurations $(-0.067)$ than in the non-original groups (-0.104 and -0.103$)$. In a fatigue loading regime (in vivo mastication), a combination of non-original abutment/implant may fail at $280 \mathrm{~N}$, that is within the range of the occlusal forces applied in the premolar region during chewing and swallowing for humans in normal conditions [39] in a very short period of time (Non-original $1: \approx 80,000$ cycles and Non-original $2: \approx 300,000$ cycles). However, at this value $(280 \mathrm{~N})$ the original abutment/implant combination will not fail. It was found that the fatigue limit for original abutments was of $280 \mathrm{~N}$ (Table 3) and therefore the original abutmentimplant connection cycling at stress levels below this limit will give infinite life. In practice, infinity may be regarded as the largest number of cycles that will be applied due to other limitations of the product life.

Failure mode was also different. Original abutments showed implant fracture in the area apical to the screw. Non-original abutments showed a failure mode where the fracture included implant and screw (Fig. 8). The SEM micrographs observation of the fractured surface of abutment screws of these nonoriginal abutments group allowed the consistent identification of fractographic markings, catastrophic or ductile failure (Fig. 9A) and fatigue striations in the fatigue zone (Fig. 9B). Surface analysis examined by other studies showed similar results $[40,41]$. The narrowest part of a component is usually its weakest part because it is the region where the maximum stresses occur [42, 43]. The study of Morgan et al [44] reported a similar failure mode: resistance to bending was reduced as the area changed from a solid cylinder to an annulus with no central screw. The idea of the abutment, screw and implant acting as a solid cylinder reinforces the authors' theory that the original abutments present a design that allows an homogeneous distribution of the forces through the assembly optimizing its mechanical behaviour.

A different design of the internal connection or screw and differences in the machining process to fabricate the collar between the three companies of the abutment could explain these differences, since the composition of the components are equal. The internal area was the one where the biggest differences among original and non-original abutments were found. The original configuration presented the smallest gap and the highest percentage of tight contact between the two connecting components.

Some limitations must be taken into consideration before transferring the results into clinical situation. This in vitro test was not able to simulate dynamic occlusion and normal loading conditions in the mouth. The numerous biological parameters that influence mechanical outcomes in vivo are not taken into account. Moreover, internal accuracy was measured using the cross-section technique only at two defined areas. Further investigation using X-ray microtomography is being carried out to evaluate internal accuracy with a 3D non-destructive technique. 
For the complete understanding of the fatigue phenomena, future developments in this matter should evaluate the effects that the use of non-original components could have on the mechanical integrity and service life of the implants.

\section{Conclusions}

Within the limitations of the present study, the following conclusions can be drawn:

- -Quality and quantity of contact among "cast-to" gold abutment-implant internal connection are superior in original abutments. Best internal accuracy determines higher grade of friction between the surfaces.

- - Resistance to cyclic loading decreases significantly (fatigue limit $\leq 225 \mathrm{~N}$ ) when non-original abutments are used, presenting a major risk of failure in a short period of time. Failure mode after cyclic loading reflected a better load distribution in original abutments and therefore lower stress concentration, providing higher fatigue resistance. These results showed that the use of original components could provide better long-term performance when restoring osseointegrated "cast-to" gold abutment dental implants.

\section{Declarations}

\section{Ethics approval and consent to participate:}

This article does not contain any studies with human participants or animals performed by any of the authors

\section{Consent for publication:}

Not applicable

\section{Availability of data and materials:}

All data generated or analysed during this study are included in this published article.

\section{Competing interests:}

The authors declare that they have no competing interests.

\section{Funding:}

The work was partially supported by the grant from Zimmer Biomet with reference Art. 83 267/2012. 


\section{Authors' contributions:}

Conceptualization: G.P; methodology: R.A, J.F.B, C.F; supervision: G.P, J.F.B.; writing original draft: R.A, J.F.B. All authors read and approved the final version of the manuscript.

\section{Acknowledgements:}

We acknowledge support of the publication fee by the CSIC Open Access Publication Support Initiative through its Unit of Information Resources for Research (URICI).

\section{References}

1. Howe MS, Keys W, Richards D (2019) Long-term (10-year) dental implant survival: A systematic review and sensitivity meta-analysis. J Dent 84:9-21. http://doi.org/10.1016/j.jdent.2019.03.008.

2. Gigandet M, Bigolin G, Faoro F, Bürgin W, Brägger U (2012) Implants with Original and Non-Original Abutment Connections. Clin Implant Dent Relat Res 16:1-9. https://doi.org/10.1111/j.17088208.2012.00479.x

3. Yilmaz B, Salaita LG, Seidt JD, Clelland NL, McGlumphy EA (2015) Load to failure of different titanium abutments for an internal hexagon implant. J Prosthet Dent 114:513-516. https://doi.org/10.1016/j.prosdent.2015.04.012

4. Tallarico M, Fiorellini J, Nakajima Y, Omori Y, Takahisa L, Canullo L (2018) Mechanical outcomes, microleakage, and marginal accuracy at the implant-abutment interface of original versus nonoriginal implant abutments: A systematic review of in vitro studies. Biomed Res Int 30 https://doi.org/10.1155/2018/2958982

5. Berberi A, Tehini G, Rifai K, Bou Nasser Eddine F, Badran B, Akl H (2014) Leakage evaluation of original and compatible implant-abutment connections: In vitro study using Rhodamine B. J Dent Biomech 5:1-7. https://doi.org/10.1177/1758736014547143

6. Solá-Ruíz MF, Selva-Otaolaurruchi E, Senent-Vicente G, González-de-Cossio I, Amigó-Borrás V (2013) Accuracy combining different brands of implants and abutments. Med Oral Patol Oral Cir Bucal 18:e332-336. https://doi.org/10.4317/medoral.18137

7. de Morais Alves da Cunha T, de Araújo RP, da Rocha PV, Amoedo RM (2012) Comparison of fit accuracy between Procera ${ }^{\circledR}$ custom abutments and three implant systems. Clin Impl Dent Rel Res 14:890-895. doi: 10.1111/j.1708-8208.2010.00323.x.

8. Mattheos N, Larsson C, Ma L, Fokas G, Chronopoulos V, Janda M (2017) Micromorphological differences of the implant-abutment junction and in vitro load testing for three different titanium abutments on Straumann tissue level implants. Clin Oral Implants Res 28:15231531. https://doi.org/10.1111/clr.13021

9. Fokas G, Ma L, Chronopoulos V, Janda M, Mattheos N (2019) Differences in micromorphology of the implant-abutment junction for original and third-party abutments on a representative dental implant. 
J Prosthet Dent 121:143-150. https://doi.org/10.1016/j.prosdent.2018.02.015

10. Tallarico M, Canullo L, Caneva M, Özcan M (2017) Microbial colonization at the implant-abutment interface and its possible influence on periimplantitis: A systematic review and metaanalysis. J Prosthodont Res 61:233-241. https://doi.org/10.1016/j.jpor.2017.03.001

11. Lopez-Piriz R, Sola-Linares E, Granizo JJ, Diaz-Guemes I, Enciso S, Bartolome J, Cabal B, EstebanTejada L, Torrecillas R, Moya J (2012) Radiologic evaluation of bone loss at implants with biocide coated titanium abutments: A study in the dog. Plos One 7:e52861. https://doi.org/10.1371/journal.pone.0052861

12. Berberi A, Maroun D, Kanj W, Amine EZ, Philippe A, Patil S (2016) Micromovement Evaluation of Original and Compatible Abutments at the Implant-abutment Interface. J Contemp Dent Pract 17:907-913.

13. Steinebrunner L, Wolfart S, Böbmann K, Kern M (2005) In vitro evaluation of bacterial leakage along the implant-abutment interface of different implant systems. Int J Oral Maxillofac Implants 20:875881.

14. Mattheos N, Janda MS (2012) Exotic encounters with dental implants: managing complications with unidentified systems. Aust Dent J 57:236-242. https://doi.org/10.1111/j.1834-7819.2012.01676.x

15. Kim JS, Raigrodski AJ, Flinn BD, Rubenstein JE, Chung K, Mancl LA (2013) In vitro assessment of three types of zirconia implant abutments under static load. J Prosthet Dent 109:255-263. https://doi.org/10.1016/S0022-3913(13)60054-2

16. Leutert CR, Stawarczyk B, Truninger TC, Hämmerle CHF, Sailer I (2012) Bending moments and types of failure of zirconia and titanium abutments with internal implant-abutment connections: A laboratory study. Int J Oral Maxillofac Implants 27:505-512.

17. Cashman PM, Schneider RL, Schneider GB, Stanford CM, Clancy JM, Qian F (2011) In vitro analysis of post-fatigue reverse-torque values at the dental abutment/implant interface for a unitarian abutment design. J Prosthodont 20:503-509. https://doi.org/10.1111/j.1532-849X.2011.00756.X

18. Alonso-Pérez R, Bartolomé J, Ferreiroa A, Salido MP, Pradíes G (2017) Evaluation of the Mechanical Behavior and Marginal Accuracy of Stock and Laser-Sintered Implant Abutments. Int J Prosthodont 30:136-138. http://doi.org/10.11607/ijp.5089

19. Vigolo P, Majzoub Z, Cordioli G (2000) Measurement of the dimensions and abutment rotational freedom of gold-machined 3i UCLA-type abutments in the as-received condition, after casting with a noble metal alloy and porcelain firing. J Prosthet Dent 84:548-553. https://doi.org/10.1067/mpr.2000.110497

20. White GE (1993) Osseointegrated Dental Technology, Quintessence, Chicago.

21. Mattheos N, Li X, Zampelis A, Ma L, Janda M (2016) Investigating the micromorphological differences of the implant-abutment junction and their clinical implications: a pilot study. Clin Oral Implants Res 27:e134-e143. https://doi.org/10.1111/clr.12578

22. International Organization for Standardization (2003) ISO Norm 11405, Dental materials-testing of adhesion to tooth structure, Genova, Switzerland. 
23. Schmid-Schwap M, Graf A, Preinerstorfer A, Watts DC, Piehslinger E, Schedle A (2011) Microleakage after thermocycling of cemented crowns--a meta-analysis. Dent Mater 27:855-869. https://doi.org/10.1016/j.dental.2011.05.002

24. Fusayama T, Katayori T, Nomoto S (1963) Corrosion of gold and amalgam placed in contact with each other. J Dent Res 42:1183-1197.

25. Odin G, Savoldelli C, Bouchard PO, Tillier Y (2010) Determination of Young's modulus of mandibular bone using inverse analysis. Med Eng Phys 32:630-7.

http://doi.org/10.1016/j.medengphy.2010.03.009

26. International Organization for Standardization (2016) ISO Norm 14801, Dentistry - Implants Dynamic loading test for endosseous dental implants. Genova, Switzerland.

27. López-Píriz R, Cabal B, Goyos-Ball L, Fernández A, Bartolomé JF, Moya JS, Torrecillas R (2019) Current state-of-the-art and future perspectives of the three main modern implant-dentistry concerns: Aesthetic requirements, mechanical properties, and peri-implantitis prevention. J Biomed Mater Res A 107:1466-1475. http://doi.org/10.1002/jbm.a.36661

28. Pérez León P, Bartolomé JF, Lombardía C, Pradíes G (2019) Mechanical fatigue behaviour of different lengths screw-retained restorations connected to two designs prosthetic connection level. J Oral Rehabil:747-755. http://doi.org/10.1111/joor.12809.

29. Morneburg TR, Pröschel PA (2002) Measurement of masticatory forces and implant loads: a methodologic clinical study. Int J Prosthodont 15:20-27.

30. Studart AR, Filser F, Kocher P, Lüthy H, Gauckler LJ (2007) Cyclic fatigue in water of veneerframework composites for all-ceramic dental bridges. Dent Mater 23:177-185.

31. Bartolomé JF, Requena J, Moya JS, Li M, Guiu F (1997) Cyclic Fatigue of $\mathrm{Al}_{2} \mathrm{O}_{3}$ and $\mathrm{Al}_{2} \mathrm{O}_{3}-\mathrm{Al}_{2} \mathrm{TiO}_{5}$ Composites in Direct Push-Pull. Fatigue Fract Eng Mater Struct. 20:789-798.

32. Bartolomé JF, Moya JS, Requena J, Llorca J, Anglada M (1998) Fatigue Crack Growth Behavior in Mullite/Alumina Functionally Graded Ceramics. J Am Ceram Soc 81:1502-1508.

33. Smirnov A, Beltrán Jl, Rodriguez-Suarez T, Pecharromán C, Muñoz MC, Moya JS (2017) Unprecedented simultaneous enhancement in damage tolerance and fatigue resistance of zirconia/Ta composites. Sci Rep 7:44922. https://doi.org/10.1038/srep44922

34. Alonso-Pérez R, Bartolomé JF, Ferreiroa A, Salido MP, Pradíes G (2018) Original vs. non-original abutments for screw-retained single implant crowns: An in vitro evaluation of internal fit, mechanical behaviour and screw loosening. Clin Oral Implants Res 29:1230-1238. https://doi.org/10.1111/clr.13390

35. Buch A (1988) Fatigue Strength Calculation. Transtech Publications, Switzerland.

36. Binon PP (1996) The effect of implant/abutment hexagonal misfit on screw joint stability. Int J Prosthodont 9:149-160.

37. Kitagawa T, Tanimoto Y, Odaki M, Nemoto K, Aida M (2005) Influence of implant/abutment joint designs on abutment screw loosening in a dental implant system. J Biomed Mater Res B Appl 
Biomater 75:457-463e. https://doi.org/10.1002/jbm.b.30328

38. Martin WC, Woody RD, Miller BH, Miller AW (2001) Implant abutment screw rotations and preloads for four different screw materials and surfaces. J Prosthet Dent 86:24-32.

39. Vallittu PK, Könönen M (2013) Biomechanical aspects and material properties, in: Nilner K, Karlsson S, Dahl BL(Eds), A textbook of fixed prosthodontics: the scandinavian approach, Gothia Fortbildning, Stockholm, 2013, pp.116-30.

40. Eckert SE, Meraw SJ, Cal E, Ow RK (2000) Analysis of incidence and associated factors with fractured implants: a retrospective study. Int J Oral Maxillofac Implants 15:662-667.

41. Piattelli A, Piattelli M, Scarano A, Montesani L (1998) Light and scanning electron microscopic report of four fractured implants. Int J Oral Maxillofac Implants 13:561-564.

42. Freitas-Júnior AC, Rocha EP, Bonfante EA, Almeida EO, Anchieta RB, Martini AP, Assuncao WG, Silva NR, Coelho PG (2012) Biomechanical evaluation of internal and external hexagon platform switched implant-abutment connections: An in vitro laboratory and three-dimensional finite element analysis. Dent Mater 28:218-228. https://doi.org/10.1016/j.dental.2012.05.004

43. Rosentritt M, Hagemann A, Hahnel S, Behr M, Preis V (2014) In vitro performance of zirconia and titanium implant/abutment systems for anterior application. J Dent 42:1019-1026. https://doi.org/10.1016/j.jdent.2014.03.010

44. Morgan MJ, James DF, Pilliar RM (1993) Fractures of the fixture component of an osseointegrated implant. Int J Oral Maxillofac Implant 8:409-414.

\section{Figures}




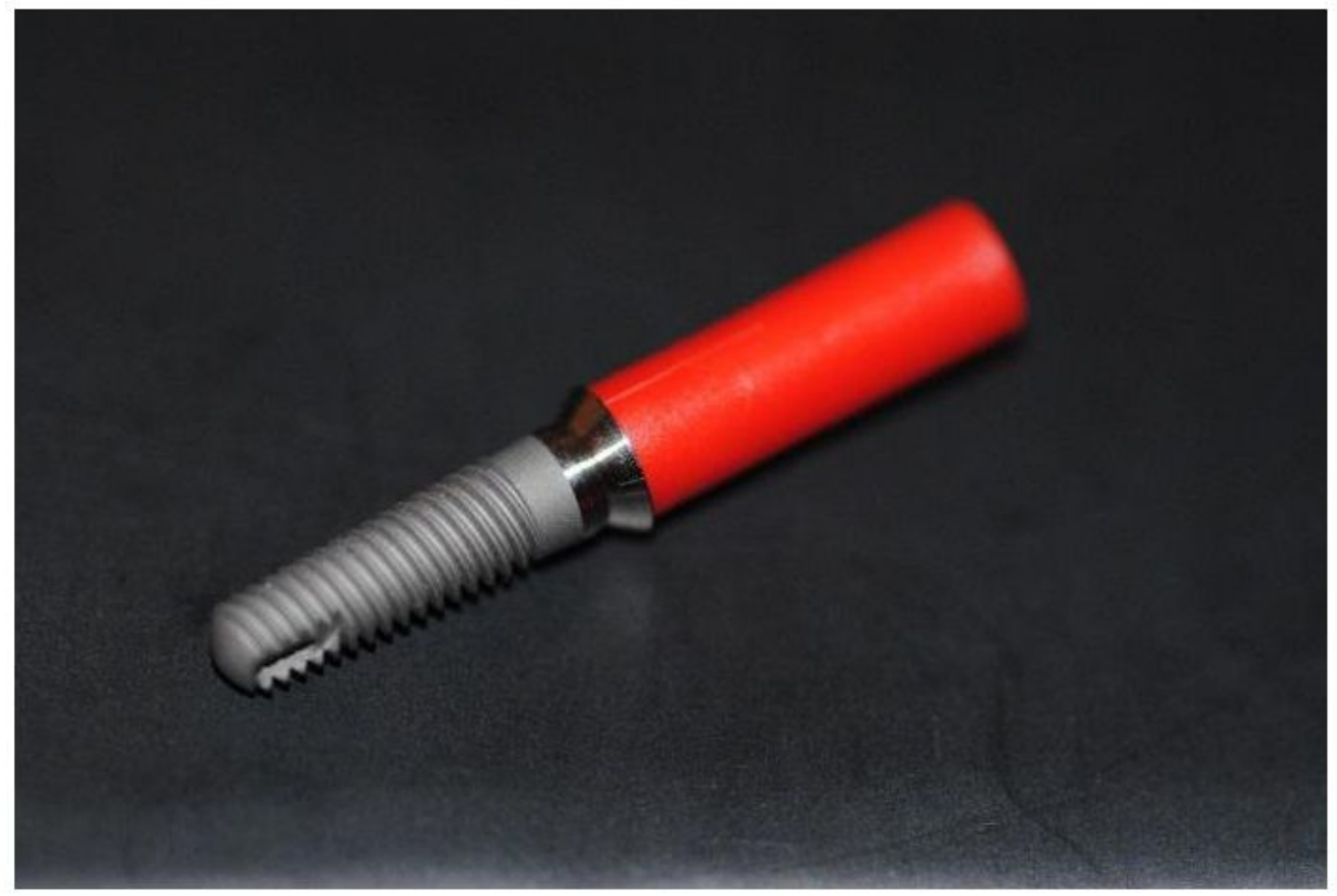

Figure 1

"Cast-to" gold abutment-implant system with a pre-machined cylinder and plastic sleeve. 


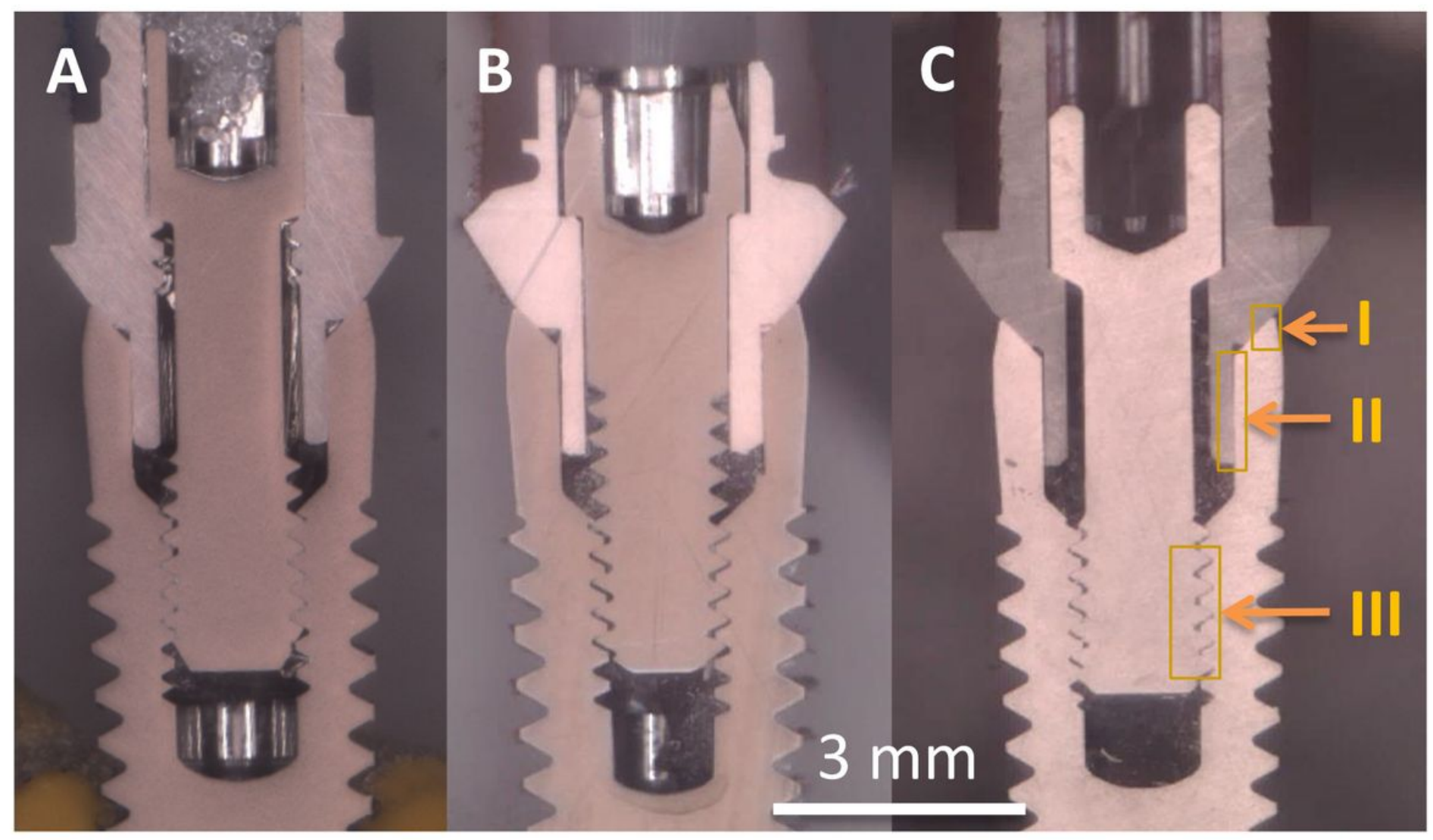

Figure 2

Representative cross section of the three implant-abutment configurations. A: Original abutment. B: Nonoriginal 1 abutment. C: Non-original 2 abutment. The three studied zones examined are indicated as follow: Platform area (I), Internal area (II) and Screw area (III).
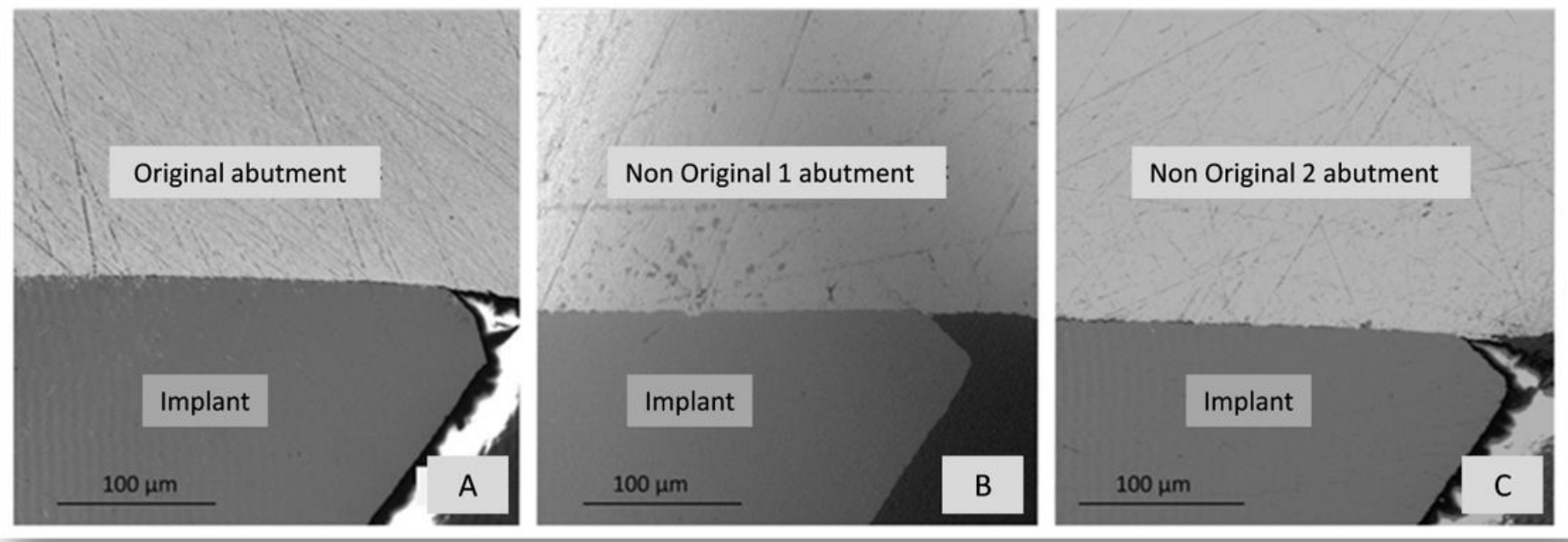

Figure 3 
Representative cross section SEM images of the different implant-abutment combinations at the platform area. A: Original abutment. B: Non-original 1 abutment. C: Non-original 2 abutment.

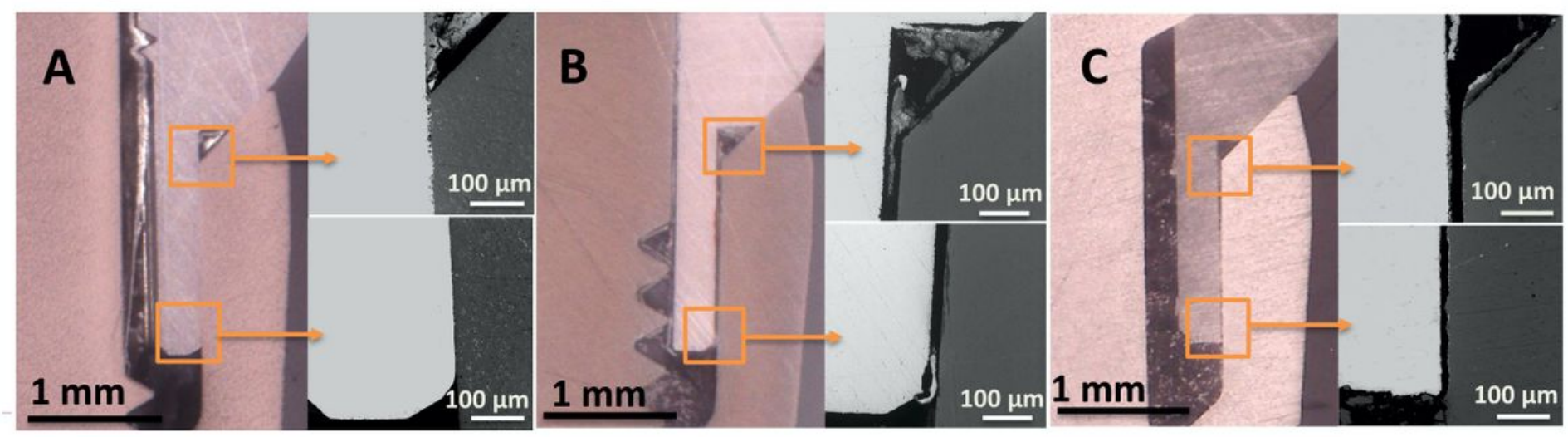

\section{Figure 4}

SEM images of the internal implant-abutment adaptation. A: Original abutment B: Non-original 1 abutment C: Non-original 2 abutment.

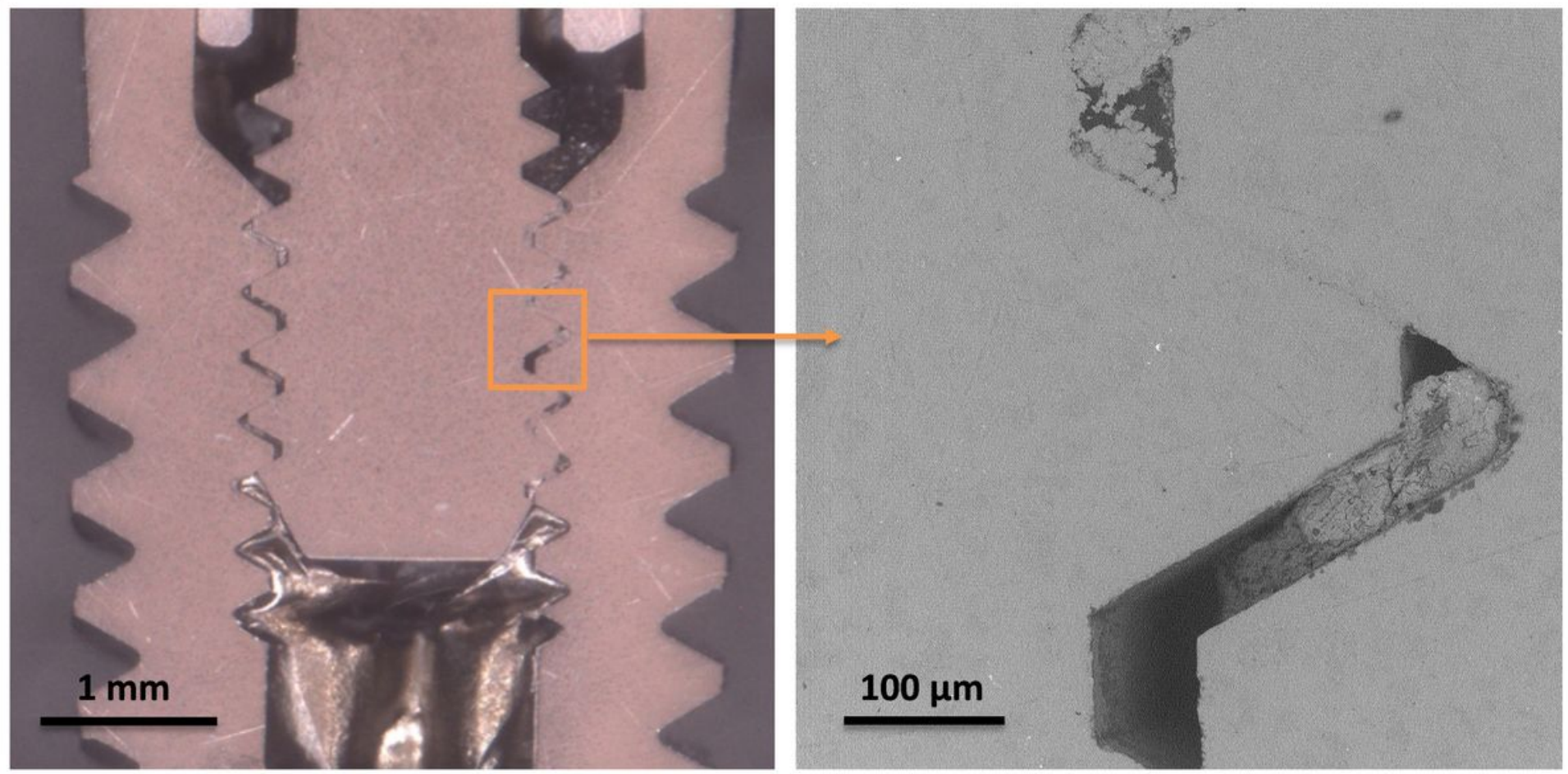

\section{Figure 5}

Representative image of an area of tight contact in the screw area of one original abutment sample. 


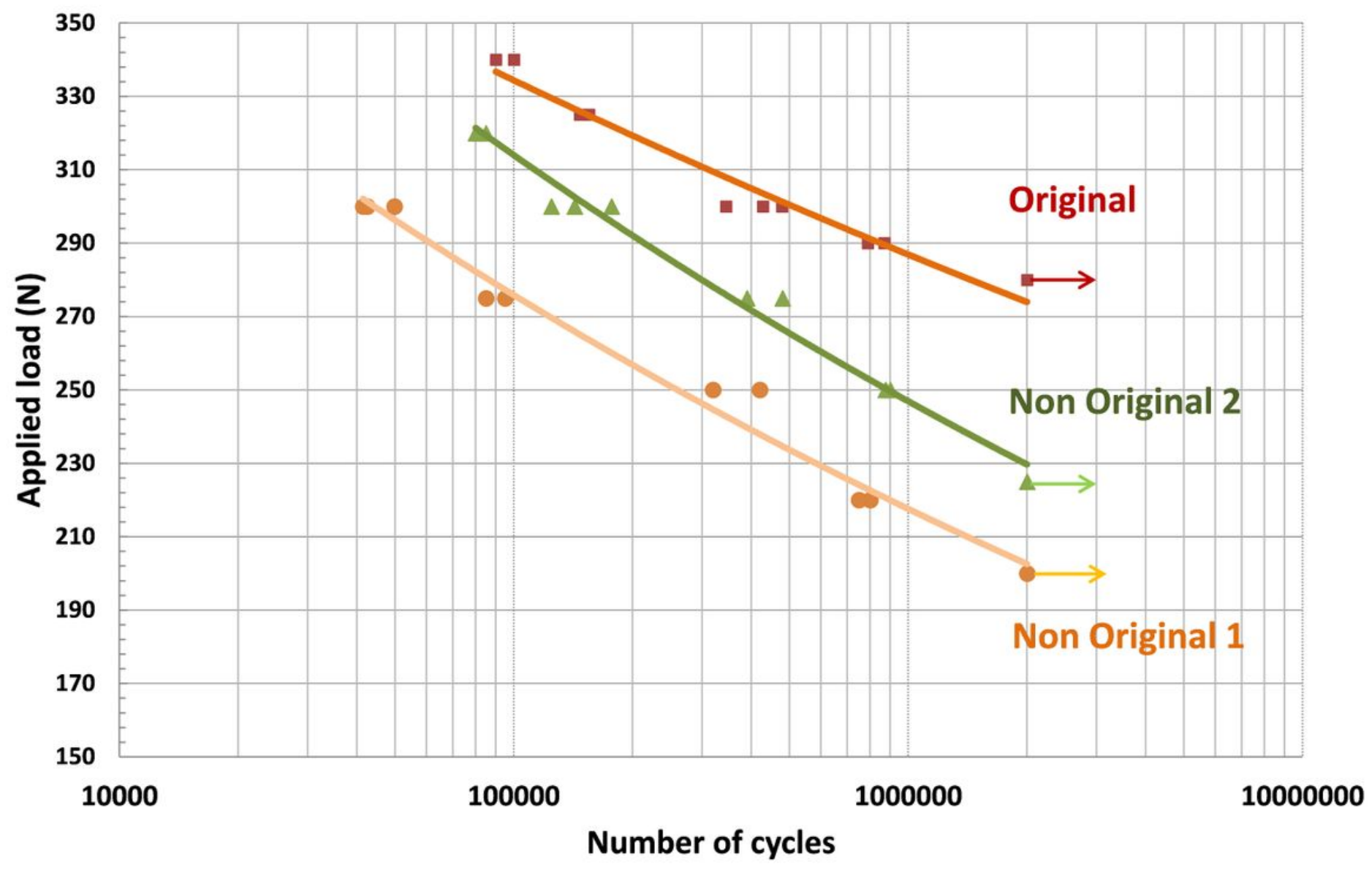

Figure 6

S-N curves for the different implant-abutment configurations showing the maximum load as a function of the number of cycles to failure. Arrows indicate run out. 


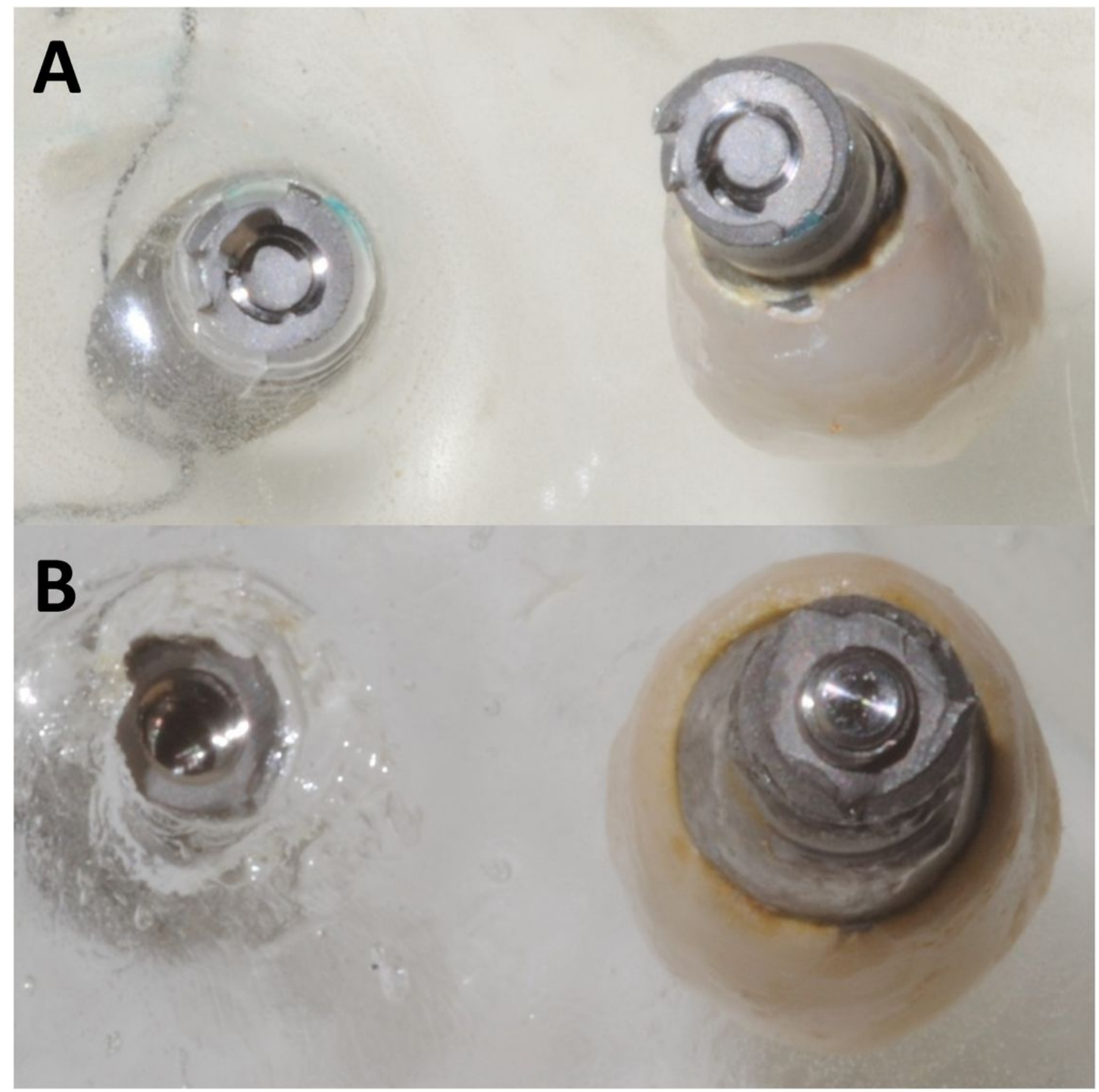

Figure 7

Representative image of the failure mode after fatigue loading: A: Non original abutments: both the implant and the prosthetic screw fractured. B: Original abutments: the fracture of the implant was apical to the end of the prosthetic screw, which was intact. 

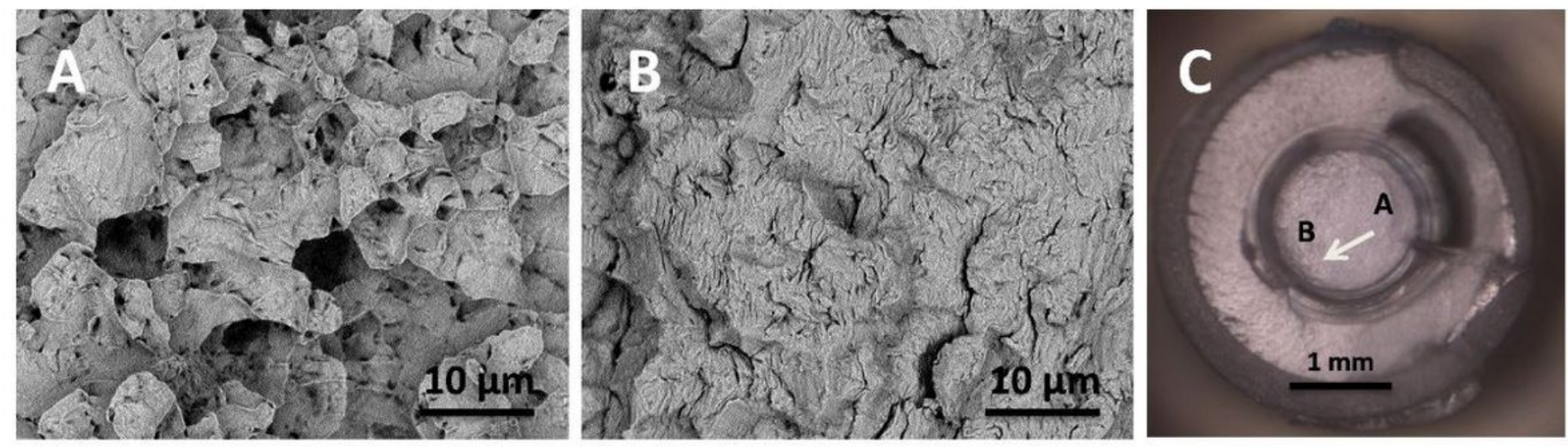

Figure 8

Representative image of a fractured surface of one specimen after fatigue test. A) SEM micrograph of fractured area in the striated or fatigue zone, B) SEM micrograph of catastrophic failure or dimples zone and $\mathrm{C}$ ) overall view with both zones (x100) with the white arrow showing the fracture direction of the abutment screw. 